A legal analysis of Australian criminal cases involving defendants with autism spectrum disorder charged with online sexual offending

Word count (manuscript, table and reference list): 12,810 


\section{A legal analysis of Australian criminal cases involving defendants with autism spectrum disorder charged with online sexual offending}

This paper examines how the symptomology of the small number of individuals with autism spectrum disorder (ASD) charged with online sexual offenses in Australia are established during legal arguments and conceived by the judiciary to impact legal liability and offending behavior. This study aims to provide empirical support for the proposition that judicial discourses regarding the connection between ASD and online sexual offending, including conduct related to child exploitation material (CEM), have little bearing on overall questions of criminal liability or use of alternative penal dispositions. It does so by exploring a sample of nine recent Australian criminal cases involving ten rulings to examine how evidence of ASD is raised in legal arguments in ways that suggest a diagnosed condition may have contributed significantly to the alleged wrongdoing. We conclude by suggesting current Australian judicial practice requires more sensitivity to the impact of clinical factors associated with ASD in shaping alternative supervisory and noncustodial dispositions for individuals convicted of online sexual offenses.

Keywords: autism spectrum disorders; Asperger's Syndrome; sexual offending; child exploitation material; legal discourse; judicial decisions

Declaration of conflicting interests:

This research did not receive any specific grant from funding agencies in the public, commercial, or not-for-profit sectors. 


\section{Abbreviations}

American Psychiatric Association - APA

Autism Spectrum Disorder(s) - ASD(s)

Child Exploitation Material - CEM

Diagnostic and Statistical Manual of Mental Disorders (Fifth Edition) - DSM-5

Queensland Corrective Services - QCS 


\section{Introduction}

Autism spectrum disorders (ASDs) are neurodevelopmental conditions characterized by restricted repetitive behaviors and impairments in reciprocal social interactions and communication (Wing, 1997). The fifth edition of the Diagnostic and Statistical Manual of Mental Disorders (DSM-5) (American Psychiatric Association [APA], 2013) identifies two core areas of impairment in ASD which are found to vary across individuals, symptoms and levels of severity. These two core domains are persistent impairments in social communication and social interaction and restricted, repetitive patterns of behavior, interests, or activities (APA, 2013). It is imperative these features inherent in ASD are recognized, diagnosed and understood, specifically in terms of how they can contribute to certain types of criminal offending, and sex offenses in particular (Ray, Marks, \& Bray-Garretson, 2004). For example, repetitive or obsessive behaviors may contribute to offenses related to child exploitation material (CEM) by individuals with ASD (Mogavero, 2016). However, there is currently a lack of clear empirical research exploring this association.

What is clear is that many individuals with ASD are found to have substantial collections of pornographic material, often involving children, or thousands of unopened computer files that are likely to have been gathered as part of the ritualistic nature of ASD. This can raise the prospect of criminal prosecution and potentially lengthy periods of incarceration or community supervision. However, individuals with ASD can be unaware of some of the broader issues regarding CEM, including where and how the files were obtained, who might be able to access them and the consequences for the minors depicted in the images. Crucially, they may not even consider something that is illegal to be so freely accessible on the internet given their literal view of the world (Mesibov \& Sreckovic, 2017). 
The case of Mr. C reported by Brendel, Bodkin, Hauptman and Ornstein (2002), aptly illustrates how ASD can be linked to an excessive obsession with pornography. Mr. C spent hours with his collection of thousands of pornographic videos and regularly accessed pornographic websites. He also had a huge collection of paper dolls that were created by using images from both mainstream and pornographic magazines that he engaged with for at least five hours per day. Mr. C reported that these activities helped to reduce his anxiety and make up for an "unrewarding life", which included a "sexual lack" in his relationship (Brendel et al., 2002, p. 167).

Individuals may also use the internet for sexual education or to satisfy sexual needs due to a lack of outlets with peers or friends (Attwood, Hénault, \& Dubin, 2014). However, despite lower than average levels of social maturity, many individuals with ASD may have an average or above average intelligence. This can create an interest in befriending people who are significantly younger than themselves but relate at the same social, emotional and intellectual levels (see Cutler, 2013). Individuals with ASD may also be completely unaware they are committing a criminal offense, as viewing CEM may result from impaired recognition of the facial expressions, such as fear, in the illicit images (Uljarevic \& Hamilton, 2013; WoodburySmith et al., 2005). Moreover, individuals with ASD may inadvertently view CEM because of their inability to correctly guess the age of the person(s) in the images, which can be exacerbated by the fact that sometimes the physical distinctions between an adult and a child can be blurry. These issues need to be considered given the illegality and severity of CEM offenses are determined by the apparent age of the victims in the images possessed by the offender (Mahoney, 2009). 
While it is clear behavioral traits associated with ASD have an impact on reducing legal culpability and sentences for various types of offenses (Allely \& Creaby-Attwood, 2016; Creaby-Attwood \& Allely, 2017; Freckelton, 2011), there is limited research examining broader trends for specific types of sexual offending in English-speaking jurisdictions. Dubin and Horowitz (2017) highlight this lack of research is closely related to the general lack of awareness amongst law enforcement agencies, criminal defense lawyers, prosecutors or judges that clients or suspects might have an intellectual disability, such as ASD, that can significantly impact interactions with justice professionals. Such conceptions of procedural fairness, as well as knowledge of the importance of appropriate diversionary strategies, is generally absent in formal legal records. While some behavioral factors related to ASD are recognized as potential mitigating explanations for certain forms of transnational online financial crime or computer hacking (Kibbie, 2012; Mann, Warren, \& Kennedy, 2018), they also have more immediate implications given the recognition that innate vulnerabilities associated with any highfunctioning males with ASD (Cooper \& Allely, 2017) may increase the likelihood of being accused of sexual offenses, particularly those involving the possession of CEM (Dubin \& Horowitz, 2017; Freckelton, 2011).

This range of intersecting factors requires detailed consideration, particularly when men diagnosed with ASD are detected and prosecuted for accessing CEM. This is particularly salient in light of the potential moral reprobation associated with any actual or virtual sexual activity with children, which can readily dilute reasoned concern over the alleged offender's neurological vulnerabilities. Our objective is to contribute to the growing body of critical knowledge about the various facets of neurolaw (McCay \& Ryan, in press), to determine how the various neurological 
and behavioural facets of ASD emerge in formal legal arguments and judicial discourses that inform determining criminal liability and sentencing specifically for CEM offences.

\section{Method}

As part of a broader examination of the prosecution of individuals diagnosed with ASD for a range of criminal offences, this study examines a sample of ten reported Australian judicial decisions between 1 January 2017 and 1 May 2018 involving defendants charged with a sexual offence involving an online component. The time period examined is significant, as it involved a relative peak in the number of reported online sex offending cases that has since continued. In each case the defendant raised evidence of ASD in an attempt to mitigate criminal responsibility, either during sentencing or as a ground of appeal. This paper focuses on Australian cases because the early pioneering work by Freckleton and List (2009) and Freckleton $(2011,2013)$ examining the impact of ASD on criminal liability and sentencing laws in Australia has been largely unrepeated. This is despite the growth of equivalent legal and socio-legal scholarship in the United Kingdom and United States (Attwood et al., 2014; Dubin \& Horowitz, 2017).

We take an empirical approach to examining how the ASD diagnosis was considered during the court proceedings. This includes presenting summary narratives of each case that reflect how legal arguments and judicial discourse view the relationship between ASD symptomology and liability or sentences for alleged CEM offenses. In this respect, we intentionally build on McCay and Ryan (in press) by examining how ASD reflects and influences a growing body of thinking aligned with the emerging field of neurolaw, and its impact on ASD cases involving online activity. We also examine several related variables, including conceptions of risk associated with the offender and offense, how the custodial 
environment might affect each suspect in light of their ASD symptoms (Mann et al., 2018), related interventions and treatment, and the suitability of any available diversionary or supervisory measures as alternatives to imprisonment.

The sample was derived from a systematic search on the Australian LexisNexis database using the terms "autism", "autistic" and "Asperger". These combined searches produced over 1,500 hits dating back to the early 1980s. These cases spanned family law and foster care disputes, and various other non-criminal issues including appeals against confiscated firearms licenses. Each case was then manually screened to identify only criminal trials or appeals where the suspected offender raised evidence of an ASD diagnosis. Each criminal case was then further screened to identify only those relating to online sexual offending, including conduct related to CEM. Table 1 summarizes key features of our sample, based on the charges, the type of case, and the determination at trial or on appeal, including the sentence where this is discernible in each ruling. 
Table 1. Specific charges, case type and outcome of cases involving online sexual offending and an individual with an ASD 1 January 2017 - 1 May 2018

\begin{tabular}{|c|c|c|c|}
\hline Citation & Charges & Case type & Outcome \\
\hline $\begin{array}{l}\text { Vucemillo v } \\
\text { Western Australia } \\
\text { (2017) WASCA } 37\end{array}$ & $\begin{array}{l}\text { CEM possession; use of } \\
\text { electronic } \\
\text { communication with } \\
\text { intent to procure a } \\
\text { person believed to be } \\
<16 \text { for sexual activity }\end{array}$ & $\begin{array}{l}\text { Appeal against } \\
\text { sentence }\end{array}$ & Dismissed \\
\hline $\begin{array}{l}\text { Dennis } v R(2017 \mathrm{a}) \\
\text { VSCA 75; (2017b) } \\
\text { VSCA } 251\end{array}$ & $\begin{array}{l}\text { CEM access \& } \\
\text { possession; failing to } \\
\text { comply with Sex } \\
\text { Offender Registration } \\
\text { Act }\end{array}$ & $\begin{array}{l}\text { Application for leave } \\
\text { to appeal against } \\
\text { sentence \& } \\
\text { subsequent appeal } \\
\text { against sentence }\end{array}$ & $\begin{array}{l}\text { Initially allowed in } \\
\text { full; subsequent } \\
\text { appeal allowed in } \\
\text { part \& resentenced to } \\
3 \text { years, } 9 \text { months }\end{array}$ \\
\hline $\begin{array}{l}R v \text { Forrest }(2017) \\
\text { NSWDC } 241\end{array}$ & $\begin{array}{c}\text { CEM possession } \& \\
\text { dissemination; } \\
\text { transmitting indecent } \\
\text { material to person }<16 \\
(\mathrm{x} 4) ; \text { use of carriage } \\
\text { service to procure a } \\
\text { person }<16 \text { for sexual } \\
\text { activity }\end{array}$ & Sentencing & $\begin{array}{l}\text { No more than } 2 \text { years } \\
\text { imprisonment } \& \\
\text { assessed for intensive } \\
\text { correction order }\end{array}$ \\
\hline $\begin{array}{l}R \vee \text { Dundas (2017) } \\
\text { QCA } 107\end{array}$ & $\begin{array}{c}\text { CEM access \& } \\
\text { possession }\end{array}$ & $\begin{array}{c}\text { Application for leave } \\
\text { to appeal against } \\
\text { sentence }\end{array}$ & Dismissed \\
\hline $\begin{array}{l}R v \text { Lane }(2017) \\
\text { NSWDC } 116\end{array}$ & $\begin{array}{l}\text { CEM possession \& } \\
\text { dissemination }\end{array}$ & $\begin{array}{c}\text { Sentencing (special } \\
\text { hearing as per Mental } \\
\text { Health (Forensic } \\
\text { Provisions) Act 1990) }\end{array}$ & 2 years, 7 months \\
\hline $\begin{array}{l}R v \text { Cecchin }(2017) \\
\text { SASCFC } 109\end{array}$ & $\begin{array}{c}\text { CEM access, possession } \\
\text { (x2) \& dissemination } \\
(\mathrm{x} 2)\end{array}$ & $\begin{array}{l}\text { Appeal against } \\
\text { sentence }\end{array}$ & $\begin{array}{c}\text { Allowed; } \\
\text { resentenced to } 4 \\
\text { years }\end{array}$ \\
\hline $\begin{array}{l}\text { Westlake v } \\
\text { Attorney-General } \\
\text { of the } \\
\text { Commonwealth } \\
\text { (2017) FCA } 1058\end{array}$ & $\begin{array}{l}\text { CEM access (x2), } \\
\text { possession \& } \\
\text { dissemination }(\mathrm{x} 2)\end{array}$ & $\begin{array}{l}\text { Application for } \\
\text { judicial review of } \\
\text { parole refusal }\end{array}$ & Dismissed \\
\hline $\begin{array}{l}\text { Attorney-General } \\
\text { (Qld) v Black } \\
\text { (2018) QSC } 29\end{array}$ & $\begin{array}{l}\text { CEM possession \& } \\
\text { dissemination }(x 4)\end{array}$ & $\begin{array}{l}\text { Hearing regarding } \\
\text { contravention of } \\
\text { supervision order }\end{array}$ & $\begin{array}{c}\text { Released into } \\
\text { community under } \\
\text { current supervision } \\
\text { order }\end{array}$ \\
\hline $\begin{array}{l}R v \text { Formenton } \\
\text { (2018) QCA } 77\end{array}$ & $\begin{array}{l}\text { CEM possession; use of } \\
\text { carriage service to } \\
\text { menace, harass or cause } \\
\text { offense }\end{array}$ & $\begin{array}{l}\text { Application for leave } \\
\text { to appeal against } \\
\text { sentence }\end{array}$ & Dismissed \\
\hline
\end{tabular}


The broad trends identified in Table 1 provide the framework for our analysis into how evidence of the suspect's ASD is introduced in legal arguments to create or apply a formal legal precedent (Mann et al., 2018). Despite significant variability in the level of detail provided regarding these issues, our discussion builds on the work of Freckelton $(2011,2013)$ to interrogate how Australian criminal courts view the innate vulnerabilities associated with ASD in light of the countervailing protective requirements that underpin criminal prohibitions and various sentencing options involving online sexual offending.

\section{Theory}

Neurolaw considers the way judges come to decisions in specific cases, through "an evaluation of the inferences of the Court about the offender's capacities as a moral agent" and "in light of the existing legal principles that bear upon the decision" (McCay \& Ryan, in press, p.

2). In this respect, concerns regarding the legal impact of ASD, specifically in relation to CEM offences, can be bracketed under three core theoretical themes.

\subsection{Risk assessment}

Exploring sexuality on the internet through CEM offers some individuals with ASD an opportunity to learn about relationships and sexuality. This does not necessarily mean viewing CEM is a logical precursor to any form of sexual offending against a minor. However, the internet and contemporary sexuality can be a "lethal combination" for some individuals with ASD (Mahoney, 2009, p. 41). As with non-offensive activities, the desire for CEM can be excessive and compulsive for individuals with ASD (Mesibov \& Sreckovic, 2017). As Sugrue (2017) indicates, there is an assumed, and potentially false, association between the level of risk 
a person poses to others, and the number and content of images collected. Therefore, it is generally assumed a greater number of images equates to a more severe obsession, which heightens the risk an individual with ASD will act on their sexual urges. Nevertheless, despite this widely held belief, findings from available empirical studies are not consistent with this association (Mahoney, 2009; Stabenow, 2011).

This questionable assumption is particularly damaging for offenders with ASD as it fails to consider the association between the volume of CEM and the compulsive and obsessive features associated with the condition. Much anecdotal evidence shows individuals with ASD charged with CEM offenses often have thousands of images or videos in their possession, many of which remain unopened or are simply hoarded. There is no established link between consuming extreme sexual content and an increased risk of dangerousness (Osborn, Elliott, Middleton, \& Beech, 2010).

\subsection{The custodial environment}

Allely's (2015) review of four studies which investigated the experience of individuals with ASD within the prison environment highlighted the potential increased risk of bullying, confrontations, exploitation, anxiety and social isolation that are directly attributable to the inmates ASD traits, such as obsessions, social naivety and impaired empathy. In this respect, it would be expected that, where possible, diversion is considered either as an alternative to criminal prosecution or as a desirable disposition after conviction provided the person with ASD agrees and is able to meet certain supervisory conditions tailored to their needs. Some supervision orders may consist of employment and counselling while others might take the form of education, psychiatric care or job training. Diversion typically occurs at the pretrial stage, 
although in most cases can be recommended at any point during a formal trial (Dubin \& Horowitz, 2017).

However, there is also relatively little understanding about the most appropriate and effective treatment programs for offenders with ASD either within or outside a custodial environment (de la Cuesta, 2010; Higgs \& Carter, 2015). Some previous studies have examined the effectiveness of, and challenges associated with, cognitive behavioral approaches in treating sexual offending for people with ASD (Murphy, Powell, Guzman, \& Hays, 2007; Ray et al., 2004) and evidence to date is not encouraging in relation to outcomes (Barkham, Gunasekaran, \& Lovelock, 2013; Milton, Duggan, Latham, Egan, \& Tantam, 2002). As such, while there is a questionable link between the use of CEM and actual risk of people diagnosed with ASD from engaging in sexual offences directed at children, there is also limited knowledge about appropriate supervision and treatment. Therefore, while considerations favorable to diversion might be met in individual cases, the moral approbation associated with any actual or virtual forms of sexual offending against children would suggest incarceration is a starting presumption during the sentencing phase.

\subsection{Malice}

Mogavero (2016) identified several studies suggesting a significant proportion of deviant or sexual offending amongst those with ASD is often driven by symptoms inherent to ASD as opposed to malice. This creates difficulties given such offenses cause physical and psychological harm to vulnerable victims and produce justifiable calls for rigorous criminal investigation and punishment (Debbaudt, 2004). However, mitigating factors must also be given appropriate weight during sentencing. This does not mean they should automatically lead to unduly lenient 
penalties disproportionate to the gravity of the offense. However, the absence of malice offers support for employing diversion particularly in relation to CEM offences (see Attwood et al., 2014; Dubin \& Horowitz, 2017), provided appropriate supervision of the offender is possible. Nevertheless, it remains difficult to strike an appropriate balance between these countervailing factors, given the competing nature of risk and vulnerability associated with the potential relationships between adult offenders with ASD, and prospective child victims in unsupervised contexts.

The absence of malice appears at two intersecting levels. First, it might diminish liability for CEM offences, as the accused does not fully intend to engage in unlawful activity or is incapable of distinguishing between right and wrong. Second, the absence of malice might undermine two key objectives of punishment, namely specific deterrence and retribution, because the person diagnosed with ASD is not fully able to appreciate their relevance either in light of the offending or when attempting to negotiate conditions within the custodial environment. This might also have bearing on whether a person with ASD is able to express remorse, which is generally factored into decisions regarding these key objectives of punishment. Notably, judicial discourses regarding these key aspects of sentencing can often make problematic inferences from psychiatric evidence that skew the objectives of the punishment, or its relationship to the behavioral patterns of an accused of convicted person. (McCay \& Ryan, in press).

\section{Results}

This section presents summaries of each case involving offenses of accessing, possessing and disseminating CEM and other related online sexual offenses. The summaries are quite detailed to capture the range of factors examined in court decisions regarding the nature of risk 
posed by the suspect, evidence of malice, and the impacts of different modes of punishment if a conviction is recorded. The cases in this sample often involved hundreds of images and videos which had been obtained over several years and were located on multiple devices in the offender's home. Two cases involved police posing as young children and interacting with the offenders online prior to the seizure of the CEM. Our objective is to provide a detailed contextual account of the factual circumstances in each case, which focuses principally on the use of expert reports outlining the relationship between the suspect's offending and identifiable psychiatric disorders, including symptoms consistent with ASD and related conditions.

\subsection{Vucemillo $v$ Western Australia (2017) WASCA 37}

Laurence Vucemillo appealed his sentence for using electronic communications with intent to procure a person believed to be under 16 to engage in sexual activity, and possession of CEM. Vucemillo placed an advertisement on Craigslist for young girls in January 2015 and police responded by posing as a 14-year-old girl to obtain evidence of explicit sexual conversations. Vucemillo was arrested during an arranged meeting with the "young girl" and CEM was later found in his house. He was sentenced to two years and six months imprisonment, which was appealed in the present case.

Ms. Zuin, a psychologist, observed that Vucemillo presented as emotionally detached, displayed a flat affect and exhibited a number of features consistent with Asperger's Syndrome, such as severe impairment with social interaction and restricted, repetitive patterns of behavior and interests. Although Vucemillo told Ms. Zuin he had a broad range of sexual interests and denied any specific interest in children, she reported that he appeared to have a marked interest in a variety of deviant sexual practices. He satisfied this deviancy by acquiring the CEM and trying to meet someone he believed to be role-playing as a 14-year-old girl. Ms. Zuin appeared to 
accept Vucemillo's belief he was communicating with an adult rather than a minor, and it was likely he struggled to meet women through conventional means due to low self-confidence and impaired interpersonal skills. This meant he became increasingly reliant on the internet to communicate with others with similar sexual urges. Ms. Zuin found Vucemillo was at a moderate to high risk of reoffending with a limited prosocial support network and few social outlets. He rarely left his house and was dependent on sexually focused social networking sites for interaction, which were noted risk factors for reoffending.

On 16 July 2016, the judge granted leave to appeal regarding the claim that Vucemillo was the victim of a miscarriage of justice because his ASD diagnosis occurred after sentencing and was therefore not considered when determining his criminal liability. This was so even though it was clear any prison sentence would prove to be unduly burdensome. A submission from Dr Brett, a psychiatrist, identified a causal link between Vucemillo's offending and mental impairment, which affected his "moral culpability for the offending" (Vucemillo v Western Australia (2017) WASCA 37 para. 35). His expert testimony is worth reproducing at length.

3. [Vucemillo's] history and presentation was consistent with the mental disorder ASD (previously called Aspergers). He described and demonstrated deficits in social-emotional reciprocity. He had difficulties in making conversation ... in the interview and he gave examples of this in the community. He also demonstrated deficits in non-verbal communication displaying a slightly restricted and incongruous affect.

4. He demonstrated a lack of mind theory .... a core symptom in autism spectrum disorders. This is the inability to put yourself in someone else's shoes or to understand their perspective.

5. He described deficits in developing, maintaining and understanding ... familial, intimate and non-intimate relationships. He has no friends and no interest in other 
people. This is a core deficit in autism spectrum disorder and appears to be very significant in his offending behaviour.

6. He finds it easier to communicate with people through his computer. He has met all of his intimate partners through his computer. He spends much of his time on his computer. People with autism spectrum disorder often find it easier to communicate with others this way as they do not need to interpret non-verbal gestures and can use emoticons to show emotions ...

8. I believe that [Vucemillo's] undiagnosed autism spectrum disorder is extremely significant in his offending behaviours. He is unable to form relationships. He uses the internet to try and make relationships. He has extremely concrete thinking. He is a stickler for rules and does not understand unwritten rules. His belief that the website was an adult only website is an example of how his autistic brain works (Vucemillo v Western Australia (2017) WASCA 37 para. 33).

In line with Ms. Zuin's assessment, Dr. Brett accepted Vucemillo's denial of sexual interest in children and his false belief that he was communicating with an adult who was pretending to be a 14-year-old girl. Dr. Brett went on to state that typically an individual with ASD would believe someone they were communicating with on an adult-only website would be an adult and would not consider the possibility it could be a minor. This "stunning naivety" (Vucemillo $v$ Western Australia (2017) WASCA 37 para. 40) is consistent with an ASD diagnosis. Interestingly, Dr. Brett did not comment on Vucemillo's possession of CEM, and did not suggest ASD would explain sexually explicit communications with someone Vucemillo believed to be role-playing as a 14-year-old girl, the possession of images of young girls in sexually provocative poses, or his general sexual interest in young girls. The symptoms of ASD reported by Dr. Brett were synonymous and consistent with Asperger's Syndrome as described by Ms. Zuin, and it was clear these were given prominent consideration during sentencing. 
During the appeal against sentence, Vucemillo also argued the combined sentence for the offenses infringed the totality principle as it did not reflect the proper relationship between the criminal conduct and his personal psychological circumstances. However, the original sentencing judge had considered these interrelated circumstances, there was no evidence prison would be more burdensome than non-custodial punishment, and the sentence would not have differed if Dr. Brett's report had been available at the initial sentencing hearing. Vucemillo had also not shown any remorse and the appeal court considered the importance of specific deterrence and overall public safety when denying this appeal against sentence.

\subsection{Dennis $v$ R (2017a) VSCA 75; (2017b) VSCA 251}

Two cases in this sample involve an application for leave to appeal and a full appeal by Stephen Dennis. Both cases were heard by the Victoria Supreme Court of Appeals and challenged a sentence of four years and six months imprisonment and permanent listing on the Victorian Register of Sex Offenders. The sentence resulted from convictions for accessing CEM using a carriage service (charge 1), failing to comply with reporting obligations under the Sex Offender Registration Act 2004 (Vic) (charge 2) and knowingly possessing CEM (charge 3). The police investigation led to the seizure of 1,410 images and 217 videos depicting mainly prepubescent children. Dennis voluntarily participated in a police interview and made admissions to the various CEM offenses. He revealed to police his use of CEM involved the following:

(a) He had obtained the material from various websites and emails over approximately five years.

(b) He had been viewing material of two young males lying on a bed, one naked, approximately one hour before the search warrant was executed. 
(c) He knew that the legal implications of owning child pornography were 'really bad' and said that 'you can get up to a long prison sentence'.

(d) When asked why he accessed child pornography he stated: 'I don't know. I can't explain it. Just something in my head [thinks] it's good ... When I saw it, I think it looks good'. He said the violent images '[don't] do anything' but that when 'it's just a naked male ... I get a good feeling ... inside of me'.

(e) He had tried to not download child pornography before but he said it's 'just like smoking' and he 'can't give it up'.

(f) He said that it is not a sexual addiction, just an addiction that makes him 'feel good inside'. He said: 'I can't explain why it makes me feel good inside'.

(g) He did not think that he could stop accessing child pornography without support (Dennis $v R$ (2017b) VSCA 251 para. 8).

The application for leave and the full appeals both relied on psychological reports tendered during the plea and sentencing. A report written by Mr. Cummins, a forensic psychologist, stated Dennis had "a very adolescent like interpersonal style" and presented as “quite a psychologically vulnerable person" (Dennis $v R$ (2017b) VSCA 251 para. 30), which is consistent with a diagnosis of ASD. This report indicated that around the age of 16, Dennis experienced a significant head injury after a motorbike accident. Mr. Cummins also believed Dennis had mild anxiety and was moderately depressed but found no evidence his sexual offending had escalated, although he showed difficulties in expressing remorse. Mr. Cummins believed a custodial sentence was inappropriate and participation in a sex offender treatment program was important. Mr. Cummins stated Dennis' risk of engaging in contact sexual offending was low and the risk of further CEM-related offenses was low to moderate.

Dr. Clayer, a senior registrar in forensic psychiatry at the Victorian Institute of Forensic Mental Health, opined that Dennis may have had a specific learning disorder or a mild intellectual disability. While Dennis presented some features consistent with ASD, Dr. Clayer 
was unable to reach a firm diagnosis, but believed he had mild to moderate depression and intermittent anxiety. She also believed Dennis used CEM to regulate his emotions, fulfilled the DSM-5 diagnostic criteria for pedophilia (see Beech, Miner, \& Thornton, 2016; First, 2014; Moser, 2016) and would benefit from participating in a sex offender treatment program. Dennis' risk of downloading and viewing CEM was assessed as moderate to high and he had previously "used child pornography as a means to regulate his emotions" (Dennis $v$ R (2017b) VSCA 251 para. 35).

Mr. Jackson, a clinical neuropsychologist, reported that Dennis had several specific impairments, including a long-standing verbal learning disorder, an average range of basic perceptual executive skills, including poor perceptual planning and organization of more complex activities, and verbal executive skills generally in the extremely low to borderline range. Dennis was also unable to learn from his errors over the past three decades, which resulted in:

... a neurophysiological condition that affects his ability to make reasoned decisions and appropriate judgements ... [and] slowed processing speed. He is overwhelmed easily and does not take a lot of information in, which is also going to affect his ability to hold on to relevant information when making decisions.

His thinking is black-and-white and he will have difficulty seeing other potential solutions ... [and] his ability to think about possible outcomes or consequences of his actions will be impacted on and impaired. People with this type of profile have a high probability of reverting back to previously learnt behaviour and this does appear to be the case ... I am of the opinion that his neuropsychological condition would have a significant impact on his ability to remember and follow any obligations that are put on him and I believe that it ... contributes to his breaches of his orders, including those related to the alleged sex offender (Dennis $v R$ (2017b) VSCA 251 para. 32). 
Mr. Jackson stated these specific issues suggested two areas of brain damage in the left frontal and right temporal lobes that were probably due to the severe traumatic brain injury Dennis sustained as a teenager. However, he also believed this neurophysiological condition was not associated with the CEM offenses and found no evident disorder affecting Dennis' impulse control, level of disinhibition, or which eroded his ability to understand the wrongfulness of his behavior. The following statement by Judge Lawson when imposing the initial sentence was reiterated during the application for leave to appeal and the final appeal.

In terms of the offending relating to child pornography, [Mr. Jackson] considered that your condition is not related to that, other than you do have a condition that makes it somewhat difficult for you to learn from your mistakes. The actual issue of child pornography or paedophilia is not related to your neurophysiological condition (Dennis v R (2017a) VSCA 75 para. 20; (2017b) VSCA 251 para. 32).

During the application for leave to appeal against the manifestly excessive nature of his sentence, Dennis argued Judge Lawson erred in finding charges 1 and 3 were serious and his level of criminal conduct was escalating. The Crown contended the sentence was reasonable because Dennis' offending was serious and continued despite prior convictions for child-related offending in 2003 and 2004. The court agreed with Dennis, indicating his sentence "stands out" (Dennis $v R$ (2017a) VSCA 75 para. 36) when compared to similar cases. It found his conduct appeared to be persistent rather than escalating to justify granting leave to appeal.

The full appeal reheard these arguments in depth, with the Crown arguing the number, duration and type of materials accessed were evidence of serious offenses that justified the original sentence. Dennis claimed that despite understanding the wrongfulness of his actions, he was not as able to appreciate their severity and was less legally culpable than an individual without his neuropsychological condition. Based on the expert opinions of Mr. Cummins and 
Mr. Jackson regarding his lack of maturity and deficits in abstract reasoning, Dennis argued he had limited moral and legal culpability due to reduced insights into the wrongfulness of his conduct. However, the Crown also noted that despite previous convictions, Dennis had reoffended and questioned the causal link between the offending and his neuropsychological condition.

The court ruled Dennis' offending was serious in both scale and duration. He was aware his actions were unlawful and it was concluded there was an inadequate causal link between his psychological condition and offending. However, the court did find an error in the degree of concurrency in relation to charges 1 and 3 that made the aggregate sentence excessive, which led to a nine month sentence reduction.

\subsection{R v Forrest (2017) NSWDC 241}

David Forrest was convicted and awaiting sentence on four counts of using a carriage service to transmit indecent material to a person under the age of 16 , using a carriage service to transmit CEM, using a carriage service to procure a person under the age of 16 for sexual activity, and possessing CEM. The offenses involved explicit online chats with young boys and

took place between 2 July 2014 and 14 January 2015. Police made contact with Forrest by using the persona of a 14-year-old boy and later seized 499 images and 199 videos from his iPad and computer.

A Community Corrections report documented that Forrest experienced several complex physical and emotional developmental problems from birth. He was born with extra digits that were surgically removed and experienced delays in speech development. The report also detailed the findings of a neuropsychological assessment performed in 2000, which found Forrest's thinking and reasoning abilities were below $98 \%$ of adults of the same age. It was therefore 
possible Forrest experienced marked impairment in a wide range of situations requiring ageappropriate thought and reasoning, including inability to fully understand social cues and anticipate the consequences of behavior.

Forrest was also assessed by Associate Professor Woods, a consultant forensic psychologist, Dr. Kneebone, a psychiatrist, and Dr. Robinson, a clinical psychologist and sex offender counsellor who had engaged in several sessions with Forrest from November 2016 to March 2017. Associate Professor Woods indicated Forrest had fulfilled the diagnostic criteria for attention-deficit/hyperactivity disorder when he was 10-years-old, with a neuropsychological assessment at that time placing his cognitive function within the borderline range. Associate Professor Woods felt this finding was particularly important when considering the nature of Forrest's actions.

However, there was only partial agreement on a diagnosis consistent with ASD. According to a Static 99R Actuarial Risk Assessment, Forrest possessed some features that potentially contributed to his offending, including deficits in intimacy, problem-solving and general social rejection, which were attributable to his developmental problems. Dr. Kneebone did not accept Forrest had ASD, although he exhibited some key symptoms. He noted Forrest's complex clinical history stemmed from the cluster of difficulties associated with his social isolation and immaturity. Forrest was aware his offending was unacceptable which would deter future reoffending, as would his experience of being in custody. However, his ongoing social isolation and cognitive difficulties had potential to raise a long-term risk of recidivism based on Forrest's understanding of the character of his conduct. When specifically asked whether Forrest had any conditions which may have contributed to his actions, Dr. Kneebone stated: 
Mr Forrest's neurodevelopmental disorders and poor social skills give rise to significant impairments of his ability to pick up on social cues or make social inference and anticipate the consequences of his behaviour. Furthermore, his low self-esteem renders Mr Forrest susceptible to pursuing avenues of gaining acceptance or validation from others, even if such methods involve deviant social activity. His cognitive and social difficulties are thought to contribute to his confusion about his sexual identity and his continual psychological denial ( $R v$ Forrest (2017) NSWDC 241 para. 61).

Dr. Robinson provided no clear determination regarding any particular intellectual impairment, or its relationship to Forrest's actions. However, he did make a number of observations, which were also endorsed by Associate Professor Woods, that suggested Forrest would be at psychological and physical risk if incarcerated and recommended continued treatment to assist with his rehabilitation.

Forrest claimed his diminished mental capacity should have been given greater consideration during sentencing. The Crown focused primarily on technical aspects of the New South Wales sentencing guidelines that determined the sentence was in parity with other similar cases based on the severity of the conduct and the need for general and specific deterrence. The Crown also questioned whether Forrest's employment history and ability with computers might "sever the casual link between his disabilities and the offending" ( $R$ v Forrest (2017) NSWDC 241 para. 118). The court found a custodial sentence of no more than two years imprisonment was appropriate and ordered a further assessment to determine the suitability of an intensive correction order. This view accepted the importance of several mitigating circumstances including the unplanned and unorganized nature of the offending, Forrest's lack of criminal history, his good prospects of rehabilitation and reduced culpability which would also magnify the impact of a long custodial sentence. 


\subsection{R v Dundas (2017) QCA 107}

Gary Dundas was convicted of using a carriage service to access and possess CEM. This case is particularly notable as it was found during the initial sentencing proceeding incarceration was likely to be onerous for Dundas because of his physical and psychiatric illnesses. Police found 36,711 images and 523 videos stored on nine different devices and evidence of three videos downloaded from file-sharing websites. Dundas was sentenced to two years imprisonment with release permitted after six months with a community-based good behavior requirement for three additional years.

Although the sentencing judge accepted Dundas had been diagnosed with Asperger's Syndrome and a hoarding disorder by Dr. Gills, a treating psychiatrist, he claimed the original sentencing judge failed to give adequate weight to the impact of his Asperger's Syndrome and related medical conditions, which could not be adequately managed whilst incarcerated. He also claimed the sentence was excessive because it was not in line with other comparable cases, he had no prior criminal history, had fully cooperated with authorities by allowing his property to be searched and by entering a guilty plea, and his hoarding disorder could partly explain why some of the CEM, which was in the lowest category of severity, had been kept for such a long time despite appearing to have been accessed regularly.

The Crown argued the aggregate number of images, which included 133 severe images and 100 videos depicting actual sexual activity, were accumulated over almost a decade and stored on multiple devices. The court found all mitigating circumstances were appropriately considered by the sentencing judge, and Dundas had not demonstrated his sentence was excessive when compared to other similar cases. There is relatively little discussion of how the 
ASD diagnosis contributed to the offending behavior compared with most other cases identified in this study.

\subsection{R v Lane (2017) NSWDC 116}

This case was a Special Hearing for sentencing under section 21 of the Mental Health (Forensic Provisions) Act 1990 (NSW). John Lane was charged with the possession and dissemination of CEM, which included 5,980 images and 54 videos stored on his mobile phone. In June 2015, Lane was found not fit to plead and referred to the Mental Health Review Tribunal. In November 2015, the Tribunal held Lane would not become fit to plead within the next 12 months due to his fixation on prior convictions for acts of indecency towards persons under the ages of ten and 16 years-of-age. He believed these convictions were wrongful and refused to discuss them. In February 2016, a Tribunal member indicated a Special Hearing was needed. This occurred in October 2016 and Lane was found guilty of both CEM charges. Three psychological reports by Ms. Robilliard, a forensic psychologist, Dr. Martin and Dr. Allnutt were central in determining Lane's fitness to stand trial and appropriate sentence.

Ms. Robilliard assessed Lane on the boundary of low to average intelligence and suggested a provisional diagnosis of ASD. Dr. Martin's assessment was consistent with this finding, adding the possibility of an underlying psychotic disorder such as schizophrenia. However, Lane's offending and previous criminal history indicated an underlying paraphilic disorder, or pedophilia. Dr. Allnutt considered Lane was not fit to stand trial due to his pathological fixation with his previous convictions, which were possibly attributable to ASD. However, the Crown submitted there was no causal connection between any recognized mental illness and Lane's offending, arguing that the "offender's condition did not impact upon his moral culpability in relation to possessing or disseminating child abuse material" ( $R v$ Lane 
(2017) NSWDC 116 para. 28). In other words, Lane was aware possessing the images was a criminal offense because he tried to hide the CEM and lied to police about losing his mobile phone.

Lane argued these reports established a direct relationship between ASD and his behavior that should have been considered during sentencing. His ASD had "significant implications for his capacity and ability to understand social interactions, to appreciate another person's perspective, to adjust his behavior appropriately, and to interact successfully with others" ( $R v$ Lane (2017) NSWDC 116 para. 37), which in turn "lowered his legal culpability" for the CEM offenses ( $R v$ Lane (2017) NSWDC 116 para. 38). In contrast, the Crown emphasized the objective seriousness of the offenses, including the volume of CEM stored in itemized folders on his mobile phone, the need for both specific and general deterrence despite the limited value of specific deterrence to someone with ASD, and Lane's apparent failure to appreciate the criminality of his conduct. Lastly, the Crown maintained Lane had an unhealthy sexual interest in young boys, and the court was obliged to consider his prior convictions for committing acts of indecency towards children. The court conceded Lane's charge of disseminating CEM involved a single image and was within the lower end of the range of severity. However, in emphasizing the need for both specific and general deterrence, the court sentenced Lane to four months imprisonment for disseminating CEM and two years and three months for the possession of CEM.

\subsection{R v Cecchin (2017) SASCFC 109}

David Cecchin appealed a seven years and five months sentence of imprisonment with a non-parole period of four years and six months for two counts of aggravated possession of CEM, two counts of aggravated dissemination of CEM and aggravated access to CEM. Cecchin 
claimed his sentence was manifestly excessive for a first-time offender who suffered from ASD who was assessed as a low risk of reoffending, lacked prior convictions and was young at the time of the offenses. He also argued the sentence failed to recognize concurrency given the factual circumstances of the offending, and the judge speculated about his prospect of reoffending despite the lack of evidence to this effect.

The ruling emphasized Cecchin's Asperger's Syndrome which was diagnosed in 1996. Dr. Begg, a psychiatrist, and Dr. Young, a psychologist with expertise in ASD, indicated Cecchin had a pedophilic disorder but presented a low risk of reoffending, even though he had little or no insight into his offending and did not appreciate its enormity. This report was submitted during the initial sentencing hearing. However, the judge did not accept Cecchin's explanations for his actions and endorsed the Crown argument that the offending was extremely serious, and the sentence was within an acceptable range. This ruling was ultimately overturned as the sentences were outside the acceptable range and wrongfully made cumulative. Cecchin was resentenced to four years with a non-parole period of two years and three months.

\subsection{Westlake v Attorney-General of the Commonwealth (2017) FCA 1058}

Daniel Westlake was convicted of two counts of using a carriage service to access CEM, two counts of using a carriage service to make CEM available and possessing CEM. He was sentenced to three years and six months imprisonment and was eligible for parole on 29 March 2017. However, he was refused parole by a delegate of the Federal Court of Australia after a recommendation by Queensland Corrective Services (QCS). Evidence indicated he had not completed a sex offender treatment program, had outstanding rehabilitation needs and had not secured appropriate post-release accommodation. Westlake sought judicial review of this decision. 
Several mental health reports were tendered in Westlake's support, including those by his clinical psychologist, Professor Attwood, child and adolescent consultant psychiatrist, Dr. Ross, and clinical psychologist, Ms. Lewis. Although the judge described the case as a very difficult sentencing exercise, a bare minimum was reached with a relatively low non-parole period to reflect Westlake's strong subjective circumstances, which included:

cooperation with investigating police; timely guilty pleas; a prior unblemished record; a sad personal history arising from recently diagnosed Asperger's Syndrome, sexual abuse suffered as a child and certain other medical conditions; an assessment of a low risk of reoffending; a finding that [Westlake] was not a suitable vehicle for general deterrence by reason of his mental condition; a finding that imprisonment

would be especially burdensome on [Westlake]; and, substantial efforts in advancing rehabilitation, including by obtaining treatment (Westlake $v$ Attorney-General of the Commonwealth (2017) FCA 1058 para. 17).

Westlake argued this favorable view at sentencing was contradicted by the QCS assessment. Specifically, the Federal Court delegate should have challenged the parole report to explore why the sex offender program had not been completed and why the residential address provided was considered inappropriate. However, neither the facts nor the relevant legislation supported these contentions, as there was no legal obligation for the court to consider any issues outside the parole board's report. Westlake's application was consequently dismissed.

\subsection{Attorney-General (Qld) v Black (2018) QSC 29}

Stephen Black was originally convicted of four counts of using a carriage service for transmitting CEM to himself and possessing CEM. He was sentenced to five years imprisonment with a non-parole period of two years and six months and released into the community on 8 February 2015 on a supervision order with 40 conditions that was due to expire in 2021. 
However, Black broke the order in June 2016, pled guilty, and was sentenced to three months imprisonment which was wholly suspended, then released from custody under the same supervision order. He then broke this supervision order twice after contacting two women and their children, pled guilty to these breaches and was sentenced to four months imprisonment in addition to the three month suspended term. The hearing in our sample placed the onus on Black to prove the existing supervision order was adequate to protect the community and justified his release into the community despite these previous contraventions.

Dr. Beech and Dr. Aboud provided expert testimony to the court. Dr. Aboud diagnosed Black with a non-exclusive type of pedophilia involving sexual urges towards prepubescent females and possible hebephilia, which refers to persistent sexual urges for pubescents. Black also presented with antisocial personality disorder with marked traits of psychopathy and features consistent with mild ASD or Asperger's Syndrome. Black had a history of pathological gambling, alcohol, cannabis and opiate abuse that reflected tendency to "deceive and manipulate ... to minimise and externalise responsibility ... [despite] at times present[ing] as a rather socially clumsy" individual (Attorney-General (Qld) v Black (2018) QSC 29 para. 16). Dr. Aboud also stated Black had:

poor adaptive coping and problem solving skills ... impulsivity ... demonstrated poor judgment ... [and] underlying psycho-social difficulties associated with his mildly autistic features that frustrate his social and communication style (AttorneyGeneral (Qld) v Black (2018) QSC 29 para. 20).

Based on the expert reports, the court was satisfied Black had established the supervision order was sufficient to protect the community as his risk of sexual reoffending was considered low to moderate. Evidence of ASD, including impairments to his capacity for concrete thought 
and social clumsiness, were considered to contribute to Black's offending and his overall presentation, which exhibited several comorbid psychopathological traits. However, reference to mild ASD is potentially problematic as it seems to suggest the symptoms are in some way nonimpairing or limit the perceived contribution of the disorder and its key symptoms to the breach of Black's order. In other words, those with mild ASD can hold down a successful job, and are highly articulate and intelligent, but may also have impaired abilities to appreciate, understand or empathize with other people that may not be fully understood by those with little or no experience of ASD. The discourses in this ruling suggest ASD is a spectrum from mild to severe, rather than a disorder with varying domains of strengths and difficulties experienced by individuals in very different ways.

\section{9 $\quad R v$ Formenton (2018) QCA 77}

Jonathon Formenton was convicted of using a carriage service to menace, harass or cause offense (offense 1) and possessing CEM (offense 2). Police seized 907 images and five videos from his mobile phone. For the first offense, Formenton was released on probation for two years without proceeding to a conviction, subject to a $\$ 500$ recognizance for good behavior. He was also required to undertake specified treatment under the direction of his probation officer. The second offense resulted in a 12 month prison sentence that was wholly suspended for two years. He sought leave to appeal these dispositions.

Formenton was assessed by several clinical experts. Dr. Keane found evidence of impairment with executive functioning, which would have an adverse impact on Formenton's ability to use intact cognitive resources in a consistent and predictable manner, which in turn may affect his social behavior. Professor McCombe, a neurologist, could not make a clear neurological diagnosis in December 2015, but considered the possibility Formenton had long- 
standing cognitive problems, which was also endorsed by Dr. Calder-Potts, a psychiatrist, who noted Formenton minimized his offenses relating to the possession of CEM.

Despite attending university, Formenton had a low IQ, was experiencing problems meeting academic requirements and was easily influenced and manipulated by others, all of which are symptoms consistent with ASD. Dr. Gardner, a clinical neuropsychologist, had met Formenton several times and found he lacked understanding and forethought regarding his CEM offense, and exhibited shock when she told him of behaviors considered to be unlawful. Dr. Robertson, a psychiatrist, believed Formenton had Asperger's Syndrome.

The judge accepted Dr. Gardner's report, emphasizing Formenton's lack of appreciation "the images that he was downloading were wrong and horrific was concerning, particularly given what [Formenton] had achieved, albeit with academic difficulties, as a person of his age" ( $R v$ Formenton (2018) QCA 77 para. 11). However, this view reflects a common misconception about defendants with ASD, as many people do not understand or believe someone who is welleducated, articulate, intelligent, or possesses an average or above average intelligence, can also be emotionally and socially impaired. The Crown highlighted a report by Ms. Bardsley, who was involved in Formenton's sex offender course, which indicated he "felt like a child in an adult's body and had no idea how to be physically intimate with someone of his own chronological age" ( $v$ v Formenton (2018) QCA 77 para. 25). This helped explain why Formenton was sexually aroused by CEM, which reinforced the delusional belief the images were not real. This lack of appreciation of the consequences of his offenses demonstrated his need for instant gratification, which compensated for his lack of knowledge and experience with age-appropriate relationships. Although he knew his actions were wrong, Formenton was unable to "progress along the continuum of intimacy in reality" ( $R v$ Formenton (2018) QCA 77 para. 25). 
Formenton claimed his sentence was manifestly excessive as insufficient weight was given to his successful completion of a sex offender's program prior to sentencing, his low risk of reoffending, the absence of prior convictions, his youth, and the overall negative impact of a conviction. He argued a three year probation order with 240 hours of community service was more appropriate. However, the Crown argued this sentence "struck the proper balance between the seriousness of the offence and [Formenton's] rehabilitation" ( $R v$ Formenton (2018) QCA 77 para. 27). The court agreed and refused leave to appeal, stating relevant personal circumstances had been considered by the sentencing judge, and the seriousness and scale of Formenton's conduct warranted a conviction.

\section{Discussion}

The cases identified in this paper reinforce a number of limits of judicial discourse that have been established in equivalent studies into neurolaw (McCay \& Ryan, in press). It highlights that courts consider a wide range of issues when faced with defendants diagnosed with ASD who are charged with online sexual offenses and the possession or distribution of CEM. This includes the relative weight given to the diagnosis against the severity or persistence of the offending $(R v$ Lane, 2017), the imposition of a cumulative rather than concurrent sentence ( $R v$ Cecchin, 2017), and various other factors commonly leading to a mild recalibration of a sentence on appeal, including the degree of cooperation with authorities, a plea of guilty, displays of remorse, and evidence of strong rehabilitation prospects (Dennis $v R, 2017 \mathrm{~b} ; R v$ Forrest, 2017; $R v$ Lane, 2017). The viability of any interim or ongoing formal supervision to limit repeat offending whilst on parole is also relevant (Westlake v Attorney General of the Commonwealth, 2017).

The overwhelming majority of psychological reports tendered in evidence in the present 
sample affirm the view the possession of extreme sexual material is not always an indication of deviant sexuality and can involve a form of "counterfeit deviance" in offenders with ASD that satisfies a naive curiosity (Mahoney, 2009, p. 21; see also Hingsburger, Griffiths, \& Quinsey, 1991). However, these impacts are seldom given credence in formal legal decisions that determine criminal liability or might lead to a non-custodial sentence. In fact, there is limited discussion of the impact of ASD on the actual nature of offending throughout this sample ( $R v$ Dundas, 2017), and several cases revealed a problematic misconception in the judicial reasoning that mild ASD or a relatively high intelligence equates to full cognitive functioning (AttorneyGeneral (Qld) v Black, 2017; $R$ v Formenton, 2018), which in turn justifies attributing full legal responsibility for the alleged crimes. Despite these limits, Australian courts are cognizant of the latitude associated with ASD diagnoses, and the need for greater knowledge and understanding of the relationship between ASD symptoms and online sexual offending. The following quote offers a pertinent illustration of these difficulties.

\begin{abstract}
Although it may be accepted that [Formenton] was afflicted by a mental disorder and/or Asperger's Syndrome, was young and naïve and unlikely to re-offend in light of his rehabilitation efforts for the State Offence, while another judge may have imposed a more lenient sentence, the sentence imposed was not manifestly excessive ( $v$ v Formenton (2018) QCA 77 para. 66).
\end{abstract}

The absence of major sentencing reductions on appeal illustrates the depth of consideration of detailed psychological reports during the initial sentencing phase. However, our analysis also identifies several issues prosecutors, defense counsel and courts must consider when reconciling the conflicting interests of suspects diagnosed with ASD and the broader protection of the community. These reflect a discursive emphasis that indicates certain characteristics of those diagnosed with ASD might be considered less relevant when determining 
their level of risk to the community, the risk of reoffending, the willingness to impose a custodial sentence in light of relevant specific and general deterrence requirements of sentencing law, and the general difficulties in determining malice. We discuss each of these issues in turn.

\subsection{Risk}

The misconception between virtual and actual risk points to the need for the adaptation of current principles for sentencing in CEM cases when the defendant has an ASD. Many leading Australian cases (Director of Public Prosecutions (Cth) v D’Alessandro, 2010; Director of Public Prosecutions (Cth) v Garside, 2016; $R$ v De Leeuw, 2015) set out detailed principles for sentencing in CEM cases which attempt to determine the objective seriousness of this type of offending, yet fail to consider the corresponding impact of ASD. The "unanimous support" (Director of Public Prosecutions (Cth) v D'Alessandro (2010) VSCA 60 para. 21; Director of Public Prosecutions (Cth) v Garside (2016) VSCA 74 para. 24) given to the number and length of time images were possessed when determining the severity of an offense or length of custodial sentence is extremely problematic for individuals with ASD. The possibility an individual with ASD will victimize minors is also limited, as their social awkwardness generally makes them unattractive to children and their naivety will make it difficult for them to manipulate potential child victims (Mahoney, 2009). This combination of factors suggests individuals with ASD pose less risk of reoffending, and any "risk of further offending by an ASD individual, especially after appropriate intervention, is less than the risk posed by a neurotypical offender" (Sugrue, 2017, p.130).

$R v$ Forrest ((2017) NSWDC 241 para. 67) is a rare example demonstrating judicial acceptance that "established Risk Assessment measures are not validated for internet-based sex 
offences" and "should not be used to assess risk of re-offence and potential for rehabilitation". Yet in Attorney-General (Qld) v Black (2018), Dr. Aboud employed a variety of risk assessment instruments, including the Static 99R Risk Matrix 2000/S, which have been found valid in predicting the risk of reoffending. Scores on these risk assessments indicated Black was a very high, high or medium risk for reoffending. On the Psychopathy Checklist, Black scored 27/40, which is a relatively high score but not above the cut-off for diagnosing psychopathy. On the Risk for Sexual Violence Protocol instrument, Dr. Aboud found Black had several positive scores, including problems with self-awareness, stress, coping, intimate relationships and nonintimate relationships, planning and supervision. Dr. Aboud considered Black's overall risk of sexual offending was high, while his risk of escalating to contact-based sexual offending was significantly lower. Various issues were considered when drawing these conclusions, including Black's "underlying psycho-social difficulties associated with his mildly autistic features that frustrate his social and communication style" (Attorney-General (Qld) v Black (2018) QSC 29 para. 20).

While experts consider the diagnosis of ASD when assessing the level of risk in most cases, how this is done is yet to be standardized. It is reasonable to assume different experts use varied or inconsistent risk assessment techniques. The level of risk in most cases in this sample was measured as high. However, current risk assessment tools do not consider the impact of ASD symptomology, and the measured level of risk may not accurately reflect the real risk an individual with ASD poses. It remains unclear how forensic mental health experts who testified in the cases presented in this sample factored this in when completing their assessment of each suspect. Moreover, none of the case reports explicitly point to any discussion or consideration that the level of risk may be lower as a result of the ASD independently of the results from these 
formal risk assessment tools. There is also no single risk assessment instrument specifically for ASD, or where CEM is the sole offense. Thus, conventional risk assessments are typically used as part of the forensic analysis where the only offenses are receipt, possession or dissemination of CEM, while clinicians and criminal justice professionals must rely on research that is limited in drawing an empirical connection between ASD and a propensity to access CEM. Therefore:

[i]n the absence of validated instruments for assessing recidivistic risk, we are forced to turn to existing research literature, which, unfortunately, is sparse when it comes to $\mathrm{CP}$ [child pornography] use and people on the spectrum. Instead, we are forced to rely on research based on neurotypicals and extrapolate based on what we know about ASD (Sugrue, 2017, p. 126).

One notable variable missing from these assessments is the relative ease with which CEM can be accessed through electronic technologies. Thus, any risk assessment places exclusive responsibility on the individual, while negating the influence of the ready availability of CEM through the world wide web.

\subsection{Impact of the custodial environment}

Several cases in this sample highlight the negative impact of imprisonment on defendants with ASD. This includes consideration of the particular vulnerabilities certain individuals experience regarding exploitation and abuse. However, it is rare for these factors to be sufficient to displace the countervailing legal demands for a term of imprisonment, which is usually justified through a combination of specific and general deterrence. For example, in Dennis $v R$ (2017b), Mr. Jackson acknowledged the negative implications of recording a conviction and imposing a sentence of "imprisonment or any other penalty", given: 
[h] will be slow to process what people are saying to him in prison, he will be overwhelmed and miss detail and he will have difficulty learning routines, etc. This would place him at significant risk of 'getting into trouble' from staff and other prisoners for not learning the rules and routines of the prison system. Because of his poor verbal executive skills, he would certainly miss any nuances [in] what people are saying to him and will take people very literally. He could potentially be at risk of being used by other prisoners to do their 'dirty work' because of his literal thinking ... [Dennis] would certainly be at risk of exacerbating any current mood condition that he has if he is sent to prison (Dennis $v R$ (2017b) VSCA 251 para. 33).

The original sentencing judge in Dennis $v R$ (2017a) referred to the opinions of three experts, Mr. Cummins, Dr. Clayer and Mr. Jackson. The following quote aptly synthesizes the consolidated views of the potentially negative impact of imprisonment in this case.

You present as a psychologically immature and vulnerable person. ... It will be difficult for you in custody and that may impact with a deterioration in your mental health condition ... I have taken into consideration the fact that imprisonment will be more burdensome for you than the ordinary gaol inmate and also there is a risk of your mental health deteriorating (Dennis $v R$ (2017a) VSCA 75 para. 50).

Similarly, in $R v$ Cecchin ((2017) SASCFC 109 para. 28), the sentencing judge found Cecchin's ASD contributed to his generally socially naïve state, which in turn would make him "more vulnerable in prison". In $R v$ Forrest (2017), Associate Professor Woods noted the deep traumatization caused by Forrest's previous experiences in custody, which exposed him to physical and sexual assaults and the ensuing psychological risks. In Vucemillo $v$ Western Australia (2017), Dr. Brett discussed particular vulnerabilities to exploitation in the prison setting and stated a lesser sentence would have been imposed if the ASD diagnosis was available for the original sentencing judge. Finally, imprisonment for two years with release to occur after 
six months in $R v$ Dundas (2017) was a direct legacy of the evidence of ASD.

Whilst I accept that some of the medical conditions you suffer can be appropriately managed in custody, it seems to me that there will nevertheless be some adverse consequence for you beyond what will be -- what would be the norm for a person being sentenced to imprisonment, and, certainly, your psychological diagnosis is likely to be a significant impact on you beyond the norm. What that means is that it is ... something that should be taken account of in the sentencing process, and there should be some mitigation of the penalty to reflect that that will be more onerous on you even though you will be sentenced to a period of actual imprisonment $(R v$ Dundas (2017) QCA 107 para. 12).

These views are consistent with expert opinion in other justice administration contexts, even though, as this sample attests, they are not always accepted in judicial discourse to justify implementing a non-custodial term or diversion for offenders who suffer from ASD (Cooper \& Allely, 2017; Mann et al., 2018). In fact, the present sample reveals this is particularly complicated when imprisonment is the benchmark for criminal punishment and community protection in CEM and substantive offences involving children, with several cases pointing to the inadequacy of current supervisory and surveillance options to limit the risk young men with ASD might engage in more problematic sexual behavior (see Westlake v Attorney-General of the Commonwealth, 2017).

While not specific to people with ASD, diversion requires inventive forms of monitoring outside the custodial setting to minimize the kinds of public stigma associated with certain forms of sexual misbehavior that commonly stem from community notification and sex offender registration requirements (Logan, 2009). This also requires expanding employment and prosocial community activities to enhance a person's integration after serving a custodial sentence. The findings in this sample suggest non-custodial forms of supervision are considered to some 
degree (see $R v$ Formenton, 2018), but their availability as meaningful pre-trial or postconviction options is presently quite limited. Moreover, the stigma of conviction itself magnifies the need to consider diversion in more cases, specifically as there is limited evidence CEM offenses evolve into a pattern of more serious contact-based sex offending (Allely \& Dubin, 2018).

\subsection{Malice, intervention and treatment}

Previous literature points to a contradiction between the degree of malice underpinning many forms of offending by people with serious mental conditions, and the conflation of legal and moral accountability for wrongdoing (McCay \& Ryan, in press). These factors are evident in the current sample, and reinforce previous research that highlights problems in attributing the full scale of legal intention for conduct that can equally be attributed to a diagnosis of ASD (Freckleton 2011; 2013). Various expert statements in the present sample regarding the suitability of certain forms of treatment that can have bearing on the ultimate question of malice, and its significance in determining whether a sentence of imprisonment is warranted in any given case. While the impact of certain treatments on judicial decision-making requires further research, it is clear from the present sample that some forms of treatment are incompatible with beliefs about men diagnosed with ASD to self-govern in absence of ongoing supervision either within or outside the custodial setting. For example, Mr. Jackson in Dennis $v R$ (2017b) suggested that narrative therapy was unlikely to be successful due to Dennis' cognitive impairments.

Left to his own devices in the community, from a neuropsychological perspective, there is a reasonably high probability of returning to previously learnt behaviour, given his difficulties learning new behaviour. The best way this can be managed is 
by having a supportive structure around him. If he was not to return to live with his former partner, then it may well be better for him to live in supported accommodation rather than just live on his own ... 'Treatment' would best be provided in the form of structure and support from organisations and others in the community to assist him in his day-to-day functioning, meeting his obligations and potentially try to learn new skills simply by learning new routines with repetition (Dennis v R (2017b) VSCA 251 para. 34).

The sentencing judge in this case also referred to Mr. Jackson's opinion that a positive rehabilitation outcome would be more likely in a supportive structure that considered Dennis' deficits. In other words, if imprisonment is considered too severe, courts must be convinced there is an adequate support and supervision structure that appears able to prevent reoffending, or at the very least improve an individual's capacity for autonomous self-governance and desistence. There is limited likelihood that malice, deterrence or retribution comes into this type of equation. Rather, it is more aligned with satisfying judicial concerns that adequate supervision of a person convicted of CEM offences can take place in the community. This reasoning might lend itself to validating incarceration as a default position, given the general absence of ongoing community supports for many individuals experiencing ASD and convicted of CEM or substantive sexual offences.

In Westlake v Attorney-General of the Commonwealth (2017), Professor Attwood emphasized a variant of this problem when describing the need for prison authorities to be aware of the impact of Westlake's symptoms when administering group treatments. The report stated:

I understand that he will be required to engage in the treatment programs designed for those in prison who have been found guilty of particular offences. It is essential that whoever is running those groups is aware of the nature of Asperger's Syndrome and how it will affect group participation. [Westlake] will have a general difficulty 
with regard to self-disclosure and especially, converting his thoughts, emotions and experiences into speech. This was clearly a characteristic in the therapy sessions with [Westlake] that I have had in the past. This is not [Westlake] being non-compliant and resistant to therapy but a genuine difficulty with group dynamics, participation and disclosure (Westlake v Attorney-General of the Commonwealth (2017) FCA 1058 para. 21).

Similarly, in Vucemillo v Western Australia ((2017) WASCA 37 para. 33), the judge referred to Dr. Brett's concern Vucemillo's “sexual deviancy was not thoroughly explored” in relation to available treatment measures while in custody. The narrative went on to state:

In my experience in working with young men with autism, their fantasy world can be very different to what occurs in reality. [Vucemillo] did describe some worrying fantasies. I would recommend that these be explored in individual counselling sessions with someone with experience in autism and sexuality (Vucemillo $v$ Western Australia (2017) WASCA 37 para. 33).

Lastly, the report by Dr. Robinson in $R v$ Forrest (2017) indicated there was no appropriate treatment available in custody. Instead, the most effective forms of one-on-one therapy or small group-based sex offender interventions were only offered within the general community. However, given such treatments are rare in the closed supervisory environments of prison, there are a series of related concerns about how their effectiveness might be managed, identified or their limitations pre-empted in the general community. In other words, while treatment is a necessary emphasis either within or outside the prison context, its impact in promoting meaningful self-regulating behavior, or enhancing the level of community supervision of people with ASD and prior CEM offences is likely to be limited, absent other forms of support that are rarely canvassed in judicial discussions regarding this type of offending. 


\section{Conclusion}

The sample examined in this study indicates some individuals with a propensity to access CEM may be subject to enhanced surveillance that leads to criminal prosecution and a custodial sentence for hoarding this material. However, such behavior does not necessarily evolve into or equate with a higher risk of engaging in more serious forms of sexual offending. It also raises many questions about intention, culpability, rehabilitation and remorse that add to the growing body of literature on the nature, application and discursive factors underpinning neurolaw and its relationship to conventional legal principles governing criminal liability and sentencing. It is important when determining criminal liability and sentences for individuals with an ASD convicted of online sexual offenses, including those specifically related to CEM, to limit, as far as possible, the harmful impacts of a formal conviction, and maximize prospects of an offender's treatment, rehabilitation and social integration through the non-punitive capacity of diversionary supervision. The cases in this sample suggest Australian courts have a considerable way to go to meet this diversionary objective, as a richer series of community-based supervision and treatment requirements is developed. However, the sophistication of the discourses surrounding ASD and further research into judicial discourses in CEM and related offenses provides a solid foundation to achieve the dual objectives of community protection and rehabilitation for men diagnosed with ASD and charged with virtual forms of sex offending.

\section{References}

Allely, C. S. (2015). Experiences of prison inmates with Autism Spectrum Disorders and the knowledge and understanding of the spectrum amongst prison staff: A review. Journal of 
Intellectual Disabilities and Offending Behavior, 6(2), 55-67. doi: 10.1108/JIDOB-062015-0014

Allely, C. S., \& Creaby-Attwood, A. (2016). Sexual offending and autism spectrum disorders. Journal of Intellectual Disabilities and Offending Behaviour, 7(1), 35-51. doi: 10.1108/JIDOB-09-2015-0029

Allely, C. S., \& Dubin, L. (2018). The contributory role of autism symptomology in child pornography offending: why there is an urgent need for empirical research in this area. Journal of Intellectual Disabilities and Offending Behaviour, 9(4), 129-152. https://doi.org/10.1108/JIDOB-06-2018-0008

American Psychiatric Association (APA). (2013). Diagnostic and Statistical Manual of Mental Disorders (5th ed., DSM-5). Washington, DC: APA.

Attwood, T., Hénault, I., \& Dubin, N. (2014). The Autism Spectrum, Sexuality and the Law: What every parent and professional needs to know. London, UK: Jessica Kingsley Publishers.

Barkham, E., Gunasekaran, S., \& Lovelock, C. (2013). Medium secure care: Forensic aspects of autism and Asperger's Syndrome. Journal of Intellectual Disabilities and Offending Behaviour, 4(1-2), 2-16. doi: 10.1108/JIDOB-02-2013-0005

Beech, A. R., Miner, M. H., \& Thornton, D. (2016). Paraphilias in the DSM-5. Annual Review of Clinical Psychology, 12(1), 383-406. doi: 10.1146/annurev-clinpsy-021815-093330

Brendel, D. H., Bodkin, J. A., Hauptman, B., \& Ornstein, A. (2002). "I see dead people": Overcoming psychic numbness. Harvard Review of Psychiatry, 10(3), 166-178. doi: $10.1080 / 10673220216216$ 
Cooper, P., \& Allely, C. S. (2017). You can’t judge a book by its cover: Evolving professional responsibilities, liabilities and 'judgecraft' when a party has Asperger's Syndrome. Northern Ireland Legal Quarterly, 68(1), 35-58. Westlaw UK. https://heinonline.org/HOL/P?h=hein.journals/nilq68\&i=39

Creaby-Attwood, A., \& Allely, C. S. (2017). A psycho-legal perspective on sexual offending in individuals with Autism Spectrum Disorder. International Journal of Law and Psychiatry, 55, 72-80. doi: 10.1016/j.ijlp.2017.10.009

Cutler, E. (2013, August 5). Autism and child pornography: A toxic combination. Retrieved from http://sexoffender-statistics.blogspot.com/2013/08/autism-and-child-pornographytoxic.html, last accessed 29 November 2018.

Debbaudt, D. (2004). Beyond guilt or innocence. Leadership Perspectives in Developmental Disability, 4(1). [forum paper from Autism New Zealand Inc.].

de la Cuesta, G. (2010). A selective review of offending behaviour in individuals with autism spectrum disorders. Journal of Learning Disabilities and Offending Behaviour, 1(2), 4758. doi: 10.5042/jldob.2010.0419

Dubin, L.A., \& Horowitz, E. (2017). Caught in the web of the criminal justice system: Autism, developmental disabilities, and sex offenses. London, UK: Jessica Kingsley Publishers.

First, M. B. (2014). DSM-5 and paraphilic disorders. Journal of the American Academy of Psychiatry and the Law Online, 42(2), 191-201. Retrieved from http://jaapl.org/content/42/2/191, last accessed 29 November 2018

Freckelton, I. (2011). Autism spectrum disorders and the criminal law. In Mohammadi, M.-R. (Ed.), A comprehensive book on autism spectrum disorders (pp. 249-272). doi: $10.5772 / 975$ 
Freckelton, I. (2013). Forensic issues in autism spectrum disorder: Learning from court decisions. doi: 10.5772/55400

Freckelton, I., \& List, D. (2009). Asperger's disorder, criminal responsibility and criminal culpability. Psychiatry, Psychology and Law, 16(1), 16-40. doi: $10.1080 / 13218710902887483$

Higgs, T., \& Carter, A. J. (2015). Autism spectrum disorder and sexual offending: Responsivity in forensic interventions. Aggression and Violent Behavior, 22, 112-119. doi: 10.1016/j.avb.2015.04.003

Hingsburger, D., Griffiths, D., \& Quinsey, V. (1991). Detecting counterfeit deviance: Differentiating sexual deviance from sexual inappropriateness. The Habilitative Mental Healthcare Newsletter, 10(9), 51-54.

Kibbie, K.S. (2012). Maleficent or mindblind: Questioning the role of Asperger's in quant hedge fund malfeasance and modelling disasters. American Criminal Law Review, 49(2), 367402.

Logan, W.A. (2009). Knowledge as power: Criminal registration and community notification laws in America. Stanford, CA: Stanford Law Books.

Mahoney, M. (2009). Asperger's Syndrome and the criminal Law: The special case of child pornography. Retrieved from https://www.harringtonmahoney.com/content/Publications/AspergersSyndromeandtheCri minalLawv26.pdf, last accessed 29 November 2018

Mann, M., Warren, I., \& Kennedy, S. (2018). The legal geographies of transnational cyberprosecutions: Extradition, human rights and forum shifting. Global Crime, 19(2), 107124. doi: $10.1080 / 17440572.2018 .1448272$ 
McCay, A., \& Ryan, C.J. (2018). Issues pertaining to expert evidence and the reasoning about punishment in a neuroscience-based sentencing appeal. International Journal of Law and Psychiatry, in press. doi: 10.1016/j.ijlp.2018.11.006

Mesibov, G., \& Sreckovic, M. (2017). Child and juvenile pornography and autism spectrum disorder. In A. Lawrence, J.D. Dubin, \& E. Horowitz (Eds.), Caught in the web of the criminal justice system: Autism, developmental disabilities, and sex offenses (pp. 64-93). London, UK: Jessica Kingsley Publishers.

Milton, J., Duggan, C., Latham, A., Egan, V., \& Tantam, D. (2002). Case history of co-morbid Asperger's Syndrome and paraphilic behaviour. Medicine, Science and the Law, 42(3), 237-244. doi: 10.1177/002580240204200308

Mogavero, M. C. (2016). Autism, sexual offending, and the criminal justice system. Journal of Intellectual Disabilities and Offending Behaviour, 7(3), 116-126. doi: 10.1108/JIDOB02-2016-0004

Moser, C. (2016). DSM-5 and the paraphilic disorders: Conceptual issues. Archives of Sexual Behavior, 45(8), 2181-2186. doi: 10.1007/s10508-016-0861-9

Murphy, G., Powell, S., Guzman, A.M., \& Hays, S.J. (2007). Cognitive-behavioural treatment for men with intellectual disabilities and sexually abusive behaviour: A pilot study, Journal of Intellectual Disability Research, 51(11), 902-912. doi: 10.1111/j.13652788.2007.00990.x

Osborn, J., Elliott, I., Middleton, D., \& Beech, A. (2010). The use of actuarial risk assessment measures with UK internet child pornography offenders. Journal of Aggression, Conflict and Peace Research, 2(3), 16-24. doi: 10.5042/jacpr.2010.0333 
Ray, F., Marks, C., \& Bray-Garretson, H. (2004). Challenges to treating adolescents with Asperger's Syndrome who are sexually abusive. Sexual Addiction and Compulsivity, 11(4), 265-285. doi: 10.1080/10720160490900614

Stabenow, T. K. (2011). A method for careful study: A proposal for reforming the child pornography guidelines. Federal Sentencing Reporter, 24(2), 108-136. doi: 10.1525/fsr.2011.24.2.108

Sugrue, D. P. (2017). Forensic assessment of individuals with autism spectrum charged with child pornography violations. In A. Lawrence, J.D Dubin, \& E. Horowitz (Eds.), Caught in the web of the criminal justice system: Autism, developmental disabilities, and sex offenses (pp. 112-139). London, UK: Jessica Kingsley Publishers.

Uljarevic, M., \& Hamilton, A. (2013). Recognition of emotions in autism: A formal metaanalysis. Journal of Autism and Developmental Disorders, 43(7), 1517-1526. doi: 10.1007/s10803-012-1695-5

Wing, L. (1997). The autistic spectrum. The Lancet, 350(9093), 1761-1766. doi: 10.1016/S01406736(97)09218-0

Woodbury-Smith, M. R., Clare, I. C., Holland, A. J., Kearns, A., Staufenberg, E., \& Watson, P. (2005). A case-control study of offenders with high functioning autistic spectrum disorders. Journal of Forensic Psychiatry \& Psychology, 16(4), 747-763. doi: $10.1080 / 14789940500302554$

\section{Cases (available from www.lexisnexis.com.au)}

Attorney-General (Qld) v Black (2018) QSC 29.

Dennis $v R$ (2017a) VSCA 75. 
Dennis v R (2017b) VSCA 251.

Director of Public Prosecutions (Cth) v D'Alessandro (2010) VSCA 60.

Director of Public Prosecutions (Cth) v Garside (2016) VSCA 74.

$R v$ Cecchin (2017) SASCFC 109.

$R v$ De Leeuw (2015) NSWCCA.

$R v$ Dundas (2017) QCA 107.

$R v$ Formenton (2018) QCA 77.

$R v$ Forrest (2017) NSWDC 241.

$R v$ Lane (2017) NSWDC 116.

Vucemillo v Western Australia (2017) WASCA 37.

Westlake v Attorney-General of the Commonwealth (2017) FCA 1058. 